Article

\title{
Trusting the People and the System. The Interrelation Between Interpersonal and Institutional Trust in Collective Action for Agri-Environmental Management
}

\author{
Jasper R. de Vries ${ }^{1, *}$, Eva van der Zee ${ }^{2}$, Raoul Beunen ${ }^{3}$, Rianne Kat ${ }^{1}$ and Peter H. Feindt ${ }^{4}$ (D) \\ 1 Strategic Communication Group, Wageningen University \& Research, PO Box 8130, 6700 EW Wageningen, \\ The Netherlands; rianne.kat@wur.nl \\ 2 Institute of Law \& Economics, Behavioural Law and Economics Group, Faculty of Law, Hamburg University, \\ 20148 Hamburg, Germany; eva.vanderzee@ile-hamburg.de \\ 3 Faculty of Management, Science \& Technology, Open University, 6401 DL Heerlen, The Netherlands; \\ raoul.beunen@ou.nl \\ 4 Agricultural and Food Policy Group, Thaer Institute for Agricultural and Horticultural Sciences, \\ Humboldt-Universität zu Berlin, 10099 Berlin, Germany; feindtpe@hu-berlin.de \\ * Correspondence: jasper.devries@wur.nl
}

Received: 18 October 2019; Accepted: 6 December 2019; Published: 9 December 2019

\begin{abstract}
Agri-environmental schemes have been introduced in numerous countries to combat biodiversity loss in agrarian landscapes that are important for both food production and biodiversity. The successful operation of such schemes depends strongly upon trust between actors involved, as well as trust in institutions that govern these schemes. However, the interplay between interpersonal and institutional trust in the context of collective action for agri-environmental management is not well understood. To address this question, we explore the case of agri-environmental management in the province of Drenthe (in The Netherlands), where a new policy model was implemented. This case shows how both institutional design and institutional performance critically influence trust dynamics. Under the old policy model, farmers struggled with auditing and control, which fostered mistrust and hampered collective action. Under the new model, a landscape approach, more responsibilities were delegated to farmers, and more room was created for interaction, which fostered trust both between actors and in institutions. Based on our findings, we conclude that institutional designs that reflect trust in the actors can foster interpersonal and institutional trust that, in turn, facilitates collective action. However, old arrangements can also create path dependencies that limit trust development and impede collective action for agri-environmental management.
\end{abstract}

Keywords: trust; collective action; agri-environmental management; the Netherlands; collectives

\section{Introduction}

Agri-environmental schemes are considered important tools for the conservation of cultural landscapes and to combat biodiversity loss [1]. Particularly agri-environmental schemes that include conservation measures, as well as restrictive measures, have the potential to enhance the conservation of biodiversity on farmland [2].

Through agri-environmental schemes, farmers can voluntarily participate in an agreement to implement certain measures on parts of their farmland that benefit biodiversity, the environment, or the landscape [3]. In return, farmers are compensated for the loss of income caused by the measures, or they are paid for measures to sustain biodiversity [4]. However, despite many efforts, 
agri-environmental policies are generally considered to be ineffective [2]. One of the main objections is that agri-environmental schemes are often too heavily based on management by individual farmers, while a collective landscape approach to conserve biodiversity that is carefully designed and targeted is required [1,2].

The lack of effectiveness and the need for collective action at landscape-level were some of the most important reasons behind the reform of the Netherlands' agri-environmental policy in 2016. Under the subsequent new policy model, agri-environmental schemes can only be implemented via regional farmers' collectives. Through these collectives, farmers cooperate to achieve agri-environmental objectives at landscape-level. In the new model, the collectives incorporate agreements, to clarify which measures are adopted on which parcels of land to achieve the collective objectives. The Netherlands was not the only EU country that adopted agri-environmental schemes in which farmers' groups played a role, as such an approach became possible under the Common Agricultural Policy (CAP) of the European Union (2014-2020) as groups of farmers became eligible for CAP payments (EU regulation 1305/2013, article 35) [5].

The new model, thus, aims to organise collective action in a particular area, rather than to pay individual farmers for adopting voluntary measures, each on their own land. The long-term performance of this new policy model depends, inter alia, upon the participation of a group of farmers. Studies have shown that the willingness to participate in agri-environmental schemes is influenced by individual factors, such as income and farm size, but also by the wider systems in which farming practices are embedded, such as the economic and political systems [6]. Several studies also point to the importance of trust in this context [7]. The role of trust in collectives, on the one hand, refers to relations between different actors (e.g., trust between farmers, or between farmers and government officials) [8], and on the other hand, to institutional trust (e.g., trust of farmers in the institutional design through which these schemes are implemented) [9]. Farmers, for example, are more willing to participate in agri-environmental schemes if they have positive experiences with such schemes or hear positive stories from their neighbours or colleagues, and believe that participation in the scheme will benefit them [6].

Although the importance of these different forms of trust is regularly mentioned, few studies actually explore how interpersonal and institutional trust interact, and how these different forms of trust are affected by particular institutional designs for collective action in agri-environmental management. A better understanding of the impact of the design of such models on trust is key to the ecological effectiveness of agri-environmental schemes because institutions influence the way in which participation, cooperation, and management practices are organised and are perceived by various stakeholders $[7,10]$ and how collective action develops $(2015$, p. 8$)$.

This study addresses this knowledge gap by exploring the interrelation between interpersonal trust and institutional trust in collective action for agri-environmental schemes. We do this by focusing on the question: "How does the institutional design of collective agri-environmental policy influence interpersonal and institutional trust and their interrelation?" In the next section, we first elaborate the theoretical perspectives on collective action and trust. Secondly, we use a case study approach to study the interrelation between interpersonal, institutional, and collective action, followed by a discussion and a conclusion.

\section{Theoretical Background: Collective Action and Trust}

Agri-environmental policy is a context in which interdependent actors are connected through "social-environmental systems that combine social organisation, human technology, biological processes and environmental systems and their services for the production of food, fibre or biomass" [11]. To collaborate in such contexts, different actors need to be willing to cooperate and coordinate their activities [12]. The design and implementation of agri-environmental policy, thus, requires cooperation and collective action between a large number of actors. 
Collective action is regarded as challenging because, just like in other complex negotiation contexts, actors involved in dealing with environmental problems often hold divergent perspectives on the issue at stake and related solutions [13]. Issues with collective action can be interpreted as non-cooperative behaviours (such as free-riding), which may impact on the effectiveness of the collective action process $[14,15]$. This can result in negative- and positive externalities, non-marketable public goods, trade-offs between the exploitation of multiple eco-system services (supporting, provisioning, regulating, and cultural), and different valuation of multiple public goods $[16,17]$.

Studies on collective action for dealing with environmental problems emphasise the importance of trust [18]. More general, studies on collective action note the importance of both interpersonal trust between actors involved and trust in institutional arrangements that guide interactions for collective action [19]. Collective action typically refers to settings where individual decisions are made independently but affect the collective outcomes [18]. Due to this dependency, collective action often leads to typical collective action problems; i.e., "whenever individuals in inter-dependent situations face choices in which the maximisation of short-term self-interest yields outcomes which leave all participants worse off than feasible alternatives" [20]. However, perceptions of feasible options and preferable outcomes might differ. The actual behaviour depends very much upon the individuals involved and the type of problem at hand [18]. It can, for example, be influenced by psychological biases, information asymmetry, and differing norms guiding which action is seen as appropriate in the specific context $[21,22]$. Through interactions, actors show the capability of learning, and through learning, actors are able to build reputations of being trustworthy or not [18]. The reputation of being trustworthy can reduce transaction costs [23] because others are more likely to take the risk of being disappointed. This can also enable collective action in contexts where individuals must choose to give up short-term personal gain for the collective benefit but cannot control whether others reciprocate. We conceptualise that reputations of trustworthiness can take two forms. On the one hand, trustworthiness refers to interpersonal trust, whereby actors trust in each other as specific well-reputed persons; on the other, trustworthiness can refer to trust in well-reputed institutions. Both types of trust are relevant in collective action situations.

\subsection{Trust}

Trust has been studied in a wide spectrum of disciplines ranging from fields such as sociology and organisational studies to environmental governance and natural resource management $[24,25]$. Consequently, many conceptualisations of trust and perspectives on the study of trust have emerged that contribute to the understanding of different aspects of trust. Trust is, therefore, mostly seen as having a multi-dimensional character [26]. This is especially evident in the field of natural resource management. Following Stern \& Coleman (2015) and other scholars [25-28], different forms of trust play a role in the management of natural resources. Based on an extensive review, Stern and Coleman (2015) define four types of trust: (1) dispositional trust, i.e., a general tendency or predisposition (with no specific reasons) to trust in social norms or social and institutional environments; (2) procedural trust, which refers to trust in systems or procedures; (3) rational trust, i.e., trust in an entity based on calculative reasoning; (4) affinitive trust, which refers to trust based on emotions, shared identities, or feelings of collectiveness. These types of trust play a role in both interpersonal and institutional trust.

\subsection{Interpersonal Trust}

Focusing more specifically on interpersonal trust, studies often mention it as a prerequisite between actors to deal with environmental problems, as an outcome of a process (trust-building interactions) and as 'lubricant' that makes cooperation possible $[27,29,30]$. Interpersonal trust has been the object of study for a long time and has received increasing attention in the last decades [31,32]. Broadly, two approaches to trust can be distinguished in the literature. The behavioural tradition looks at trust based upon the observable actions of others in an experimental setting [33,34]. The cognitive tradition focuses on cognitive aspects, such as uncertainties, risks, and expectations, as the basis for trust or 
distrust $[35,36]$. The distinction between the two is mainly analytical, and in real-life interactions, both aspects play a role.

In addition to these two lines of research, attention is increasingly given to the dynamic nature of interpersonal trust [36]. This dynamic approach to interpersonal trust focuses on how trust develops over time, and how it is both influencing and influenced by the interactions between actors, leading to both more calculative as well as more affinitive reasons for trust or distrust. Such an approach takes into account the dynamics that characterise the negotiations and interactions within collective action [36-38].

From a dynamic perspective, interpersonal trust can be conceptualised as individuals' expectation about the thoughts, behaviour, and decisions of other people within a specific trust context, based upon past experiences and their interpretation $[39,40]$. These expectations are constantly revised in the light of new experiences, interactions, unfolding information about others and changing contexts [41]. These experiences add to the collective history and the perspective thereof, resulting in changed expectations and giving rise to ever-changing trust dynamics. As such, interpersonal trust relations are constantly subject to change [42].

\subsection{Institutional Trust}

Institutional trust generalises trust beyond a specific interpersonal relation [43] and pertains to the broader context in which interactions take place. Often, institutional trust forms the basis for expectations towards individuals that are not familiar. In other words, institutions have the ability to generalise trust among individuals [44] and precede interpersonal trust relations. Paradoxically, to function in this way, institutions themselves must be trusted, as institutional trust is regarded as crucial for the performance of institutions and their enabling and structuring characteristics $[45,46]$.

Trust in institutions, also referred to as systems trust or confidence, is often defined as the unconscious expectation that institutions will work as they always did, and is based on long-standing experiences of the functioning of these institutions [47,48]. Such trust is partly based on their procedural capacity, i.e., on procedural trust, as well as more generalised or dispositional forms of trust $[24,27]$. Well-designed institutional arrangements enhance the stability of institutions, giving scope for further variations or specifications that fit specific contexts or cooperation contexts [49]. However, strong and trusted institutions might also create path-dependencies, from which it is hard to diverge [50]. This does not mean that institutional trust does not change. Institutions failing to perform can suddenly, or more gradually, experience a decline in trust, or cause trust to decline more broadly [51], a development that can further undermine institutions and their performance. Trust in institutions is practically hard to restore. Consequently, institutional trust is often considered as a more stable type of trust that has a lower dynamic then interpersonal trust and is affected by institutional performance and design.

\subsection{The Interrelation between Institutional Trust and Interpersonal Trust}

Interpersonal and institutional trust are two connected constructs [47]. Institutional trust is a specific response to the complexity of modern society, based upon a large number of interdependent interactions across large distances in space and time [52]. Therefore, institutional trust forms the context of trust in interpersonal interactions, and trusted institutions are the guarantor of interpersonal trust relations [53]. As such, institutional trust has a great influence on interpersonal trust [51]. However, interpersonal trust also has a great influence on institutional trust, as it may be extended to strangers, based on shared norms, and a sense of shared identity. Such shared norms may evolve into informal and formal rules, supporting social exchange, and promoting institutional trust [54]. However, in other contexts, a mismatch can occur as institutional trust may prevail, but trust in a person representing the institution (e.g., government and government official) may be absent (or the other way around) [24,28]. Coleman and Stern (2018) state that the possible configurations between the two are nearly endless, especially as such relations refer to specific trust on different levels and in specific trust contexts. 
In summary, institutional trust forms the context within which interpersonal trust develops, while interpersonal trust relations can also influence trust in institutions.

From our theoretical exploration, it follows that trust is a concept with a strong multi-dimensional character, in which interpersonal trust is highly dynamic under the influence of new experiences, altered expectations, and contextual changes, while institutional trust is less dynamic and relates to the design and performance of institutions. However, both types of trust are interrelated in complex ways as trust is experienced on different levels and in different contexts may contribute to either trust in institutions or interpersonal trust as well as their interrelation. For studying trust and the performance of agri-environmental policies as collective action, we have to look at institutional design and performance, and how these impact interpersonal and institutional trust and their interrelation. In doing so, we must take into account the wider socio-ecological context in which agri-environmental policies are embedded (see Figure 1).

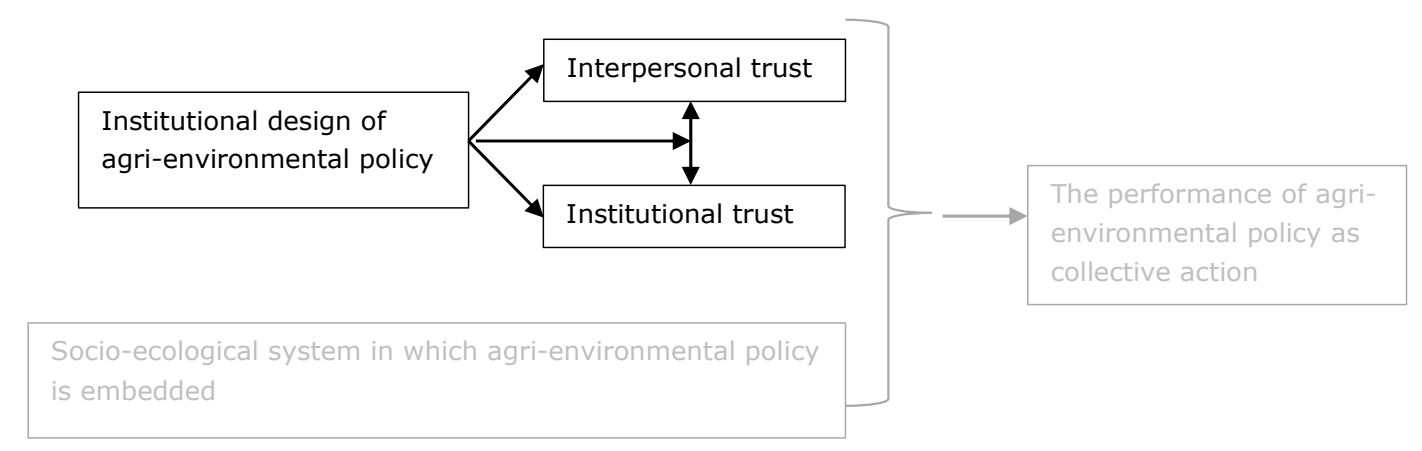

Figure 1. Conceptual framework.

\section{Methods}

Drawing on the theoretical considerations, three interrelated research questions can be formulated for analysing how the institutional design of agri-environmental policy influences interpersonal and institutional trust and their interrelation. First, what is the role of institutional trust, and how does it structure collaboration? Second, what is the role of interpersonal trust in these collaborations? Third, how do interpersonal and institutional trust influence each other? To answer these questions, we used a case study methodology to gain insight into institutional design, the role of institutional trust, interpersonal trust, and collective action in agri-environmental policy.

\subsection{Case Study Design}

A case study design was deemed appropriate as it allows the in-depth analysis of a specific phenomenon in its local context $[55,56]$. Case study design is especially suitable for exploratory research, in which understanding is the primary objective, and the phenomenon under investigation is difficult to quantify, not well understood, and needs to be studied within its natural setting [55].

We selected the case of agri-environmental management in the province of Drenthe (The Netherlands). For the selection of the case, we looked at the different agricultural collectives in the Netherlands and the diversity of the landscape under management and related measures, as we aimed for a case that would include different types of landscapes and related biodiversity goals in order to prevent analysing only one set of agri-environmental measures. Second, we considered the duration of time that the different cooperatives had been working under the new policy model as it had not been implemented throughout the Netherlands at the same time. We aimed for a collective that was already working under the new policy model for several years in order to allow a thorough analysis. Third, we looked at the territorial unity. In doing so, we aimed for a case that was made up of logical territorial unities in the sense of administrative boundaries and identity, not specially made up 
for the new policy model. In addition, the case should allow for studying a diverse group of actors (farmers and other stakeholders) negotiating over agri-environmental management.

\subsection{Case Introduction}

The province of Drenthe (see Figure 2) is situated in the northern part of the Netherlands and comprises around, 2600 square kilometres. For Dutch standards, the province, with just under 500,000 inhabitants, has a low population density of about 200 persons per square kilometre. It is characterised by a diverse landscape with extensive natural creek systems in the north, forest and higher sand grounds running from north to south-east, large wetlands (peat and heather), and vast agricultural areas, partly on former peatland. The cooperative Agricultural Nature Drenthe (AND) has over 200 members (farmers) that participate. Their farms mainly produce arable crops ranging from potatoes to sugar beets and grains, as well as dairy products. Consequently, the agri-environmental schemes mainly focus on cropland field edges and leaving parts of the grains unharvested so they can serve as bird feed during the winter. The province does not have any large cities or industries, making agriculture as well as tourism important economic sectors.

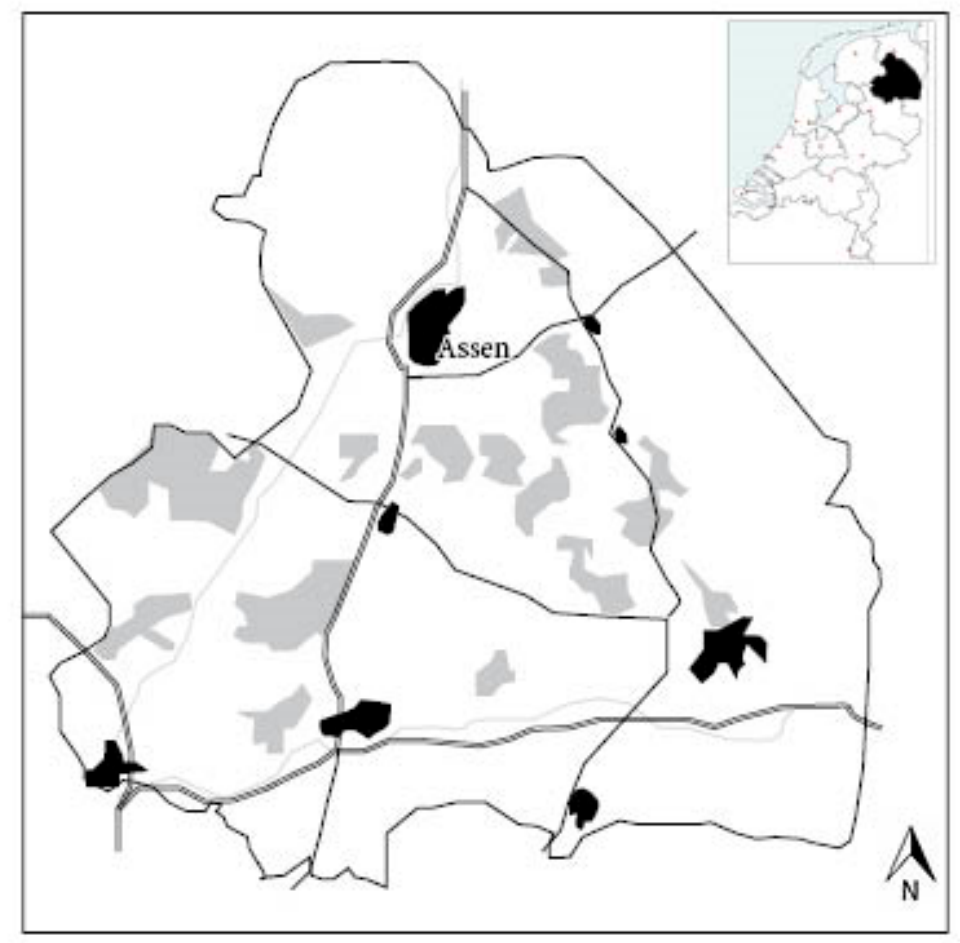

Figure 2. Province of Drenthe with urban areas (black), main road network (blacklines), nature areas (grey), and water (grey lines).

\subsection{Interview Design}

Data were gathered through semi-structured interviews between April 2018 and May 2019, and through the analysis of policy documents. In total, 16 interviews were conducted with 20 people. Most interviews were held one-on-one. However, some farms were run by a partnership of brothers or father and son, while in interviews with (governmental) organisations, sometimes two people were involved based on complementary expertise. This resulted in interviews with two interviewees at the same time. To cover the diversity of farms, 6 dairy and crop farmers were interviewed, with both organic and conventional farmers in each group. To cover the direct network around farmers and the collective, representatives working at the office of the collective Agricultural Nature Drenthe (AND) were interviewed, as well as two important buyers and input providers (for crops Agrifirm, for dairy Friesland Campina). To cover the wide network of organisations involved, representatives of all 
relevant governmental bodies were interviewed (Province, National government, European Union, and the executive body of the provinces). In addition, the NGO coordinating interactions between the different collectives in the Netherlands was interviewed, as well as three nature organisations (NGO's): one involved in auditing at the national level, one involved at the provincial level, and one involved in landscape management on provincial level (see Table 1). The interviews were held in Dutch, took about one-and-a-half hours, and were audiotaped. On the initiative of the interviewees, interviews were accompanied by field visits.

Table 1. Overview of interviewees.

\begin{tabular}{ccc}
\hline & \# Interviewees & \\
\hline Farmers & 6 & Crop, dairy and organic \\
\hline Government officials & 6 & $\begin{array}{c}\text { Province, national, European } \\
\text { Union, executive body }\end{array}$ \\
\hline Farmers collective & 2 & Drenthe (province) \\
\hline Nature organisations & 3 & National level, provincial level. \\
\hline Farmer collectives representative & 1 & National level \\
\hline Supply companies & 2 & Dairy and crop \\
\hline
\end{tabular}

The interviews were semi-structured around a list of themes and questions. These themes were based on the theoretical framework and focused on experiences with the old and the new policy model, how the models structured collaboration (RQ1), how it influenced social relations, specifically trust (RQ2) in other actors, institutions, and the policy itself (RQ3). Under these five themes, 29 questions were asked. This approach was chosen to give the interviewees the opportunity to share their perspective on the particular matter. The interview topics focused on various events and experiences with agri-environmental management on farmland over time and compared the new and old policy models. In addition, interviewees were given the opportunity to share topics that were not raised by the interview but felt to be relevant to their perspective.

After the interviews, the audiotapes were transcribed. This data was analysed using coding. In the first round of coding, the focus was on the specific concepts presented in the theoretical section (interpersonal trust, institutional trust, and collective action), and how they were discussed by the interviewees. In the second round of coding, these findings were related to each other and to the policy models in order to establish the interrelation between interpersonal trust, institutional trust, and institutional design. In the third round of analysis, the quotes were structured over time to reconstruct experiences with the old and the new policy models, and how these experiences influenced each other. This structure guided the presentation of the results, as shown in this paper.

\subsection{Potential Limitations}

This research focusses on the relation between institutional design and interpersonal and institutional trust. To do so, we focused on the case of agri-environmental schemes in the province of Drenthe and their experiences with two successive policy models. Through interviews, we aimed to cover all the perspectives and experiences present amongst the actors involved, including a wide and diverse range of actors. However, the network is extensive, and agri-environmental management in Drenthe alone already includes over 200 farmers. Consequently, only a minor share of the involved actors were interviewed. However, the interviews reached a point of theoretical saturation, i.e., in the last interviews, we did not observe new information or themes in the data on the role of interpersonal trust and institutional trust that would have justified further interviews in the case study region. 


\section{Results}

\subsection{Short History of Agri-Environmental Management on Farmland in the Netherlands}

Nature management on farmland has been practised for decades under various successive agri-environmental policies in the Netherlands. The aim of these policies was to improve biodiversity in the Dutch rural areas outside designated protected natural areas. These policies were based on voluntary management schemes under which farmers went into an agreement with the Dutch Government to adopt specific management measures on parts of their farmland that would benefit biodiversity, the environment, or the landscape. Such measures included, but were not limited to, sowing flower seeds on farmland, delayed mowing of grass to support ground birds, and leaving part of the grain unharvested so that food was still available for birds in the winter. The farmers were compensated for the loss of income caused by the measures taken. Each individual farmer could make an agreement with the Dutch Government, after which the relevant governmental agency checked if all obligations were met and handled the payments. This model resulted in a lot of administrative duties for both farmers and governmental agencies. Minor administrative mistakes often caused a lot of friction and irritation between the partners involved and delayed administrative processes. Consequently, the model became associated with high transaction costs and mistrust. Furthermore, in this model, there were almost no informal, direct relations between the governmental agency and individual farmers. From an ecological perspective, the model also faced a lot of critique and was regarded as ineffective, because it addressed individual farmers and their farmland instead of larger contiguous farm areas that are essential for biodiversity [57,58]. For this reason, the new Agrarian Nature and Landscape Management policy (Dutch acronym: ANLb) was introduced in 2016 (hereafter is referred to as the new model). In the new policy model, coordination was transferred from the Dutch Ministry of Agriculture to provinces and farmers' collectives (a total of 40 for the entire Netherlands). In this model, there are more informal and direct relations between the actors involved, as, for example, farmers need to discuss measures and environmental outcomes. The new model resulted in changing actor networks and ways of working that have given rise to new dynamics and changing relations.

\subsection{Experiences with the Old Model}

In addition to the critique of the effectiveness of the old model for agri-environmental schemes, it also led to negative experiences among farmers and government officials. For farmers, especially, the administrative processes created uncertainties and risks as small mistakes could result in financial penalties. Government officials, on the other side, were especially unsatisfied with the (mostly indirect) mode of cooperation with the individual farmers and the high transaction costs involved. These negative experiences strengthened the feeling among farmers that 'those people of the Ministry' were not knowledgeable about their local situation. As a consequence, a decreasing trust among farmers and farmers' organisations in the Ministry of Agriculture (LNV) and the policy could be observed. The main reason for this was that: "the old policy represented a lot of problems and bureaucracy", as a farmer explained. This point was also underlined by a civil servant of the province: "the old model was more bureaucracy, we had 330 contracts to manage."

Because the policy targeted individual farm operations, all farmers had to fill in data forms about their land and file them directly to the Ministry of Agriculture. Consequently, none of the actors experienced the policy as collective action: "We were working on our own," remarked a farmer. "And we never discussed it with others", another one added. Over time, a common feeling emerged among the farmers that they had become dependent on the Ministry of Agriculture. This decreased trust and created mistrust towards ministerial staff and related executive management organisations, making it more difficult to reach agreements. At the same time, various government agencies and nature organisations were critical about farmers in the old policy: "The farmers at that time were real 'post-WWII' farmers, educated to produce, not to take care of the landscape," remarked a Dutch government official, while a conservation manager explained: "especially the young farmers, they know nothing about biodiversity, they 
are only educated to produce". These experiences show that the way that the policy was organised created an individualistic focus, undermined any feeling of a common responsibility and led to uncertainties (risk of small but expensive errors) among actors involved. These experiences resulted in mistrust between farmers and officials and a general feeling of mistrust towards the agri-environmental policy.

\subsection{The New Policy Model}

The start of the new model and the concurrent introduction of farmers' collectives faced some difficulties after the experiences with the old model. In particular, the mutual feelings of mistrust made a long-standing discussion necessary about the freedom that should be given to farmers and collectives, and the role of monitoring and auditing the progress and results. As one of the auditors recollected: "The collectives [i.e., the new model introduced by The Netherlands] nearly didn't make it", which was also underlined by an interview partner from the province: "The process towards the new model was a tough one, but we are happy now." The complicated establishment of the new model resulted in the involvement of a wide range of organisations, including governmental bodies, nature organisations, and farmers. In this structure, farmers were organised into collectives which develop their agro-environmental plans together with the provinces. In turn, at national-level, BoerenNatuur (an agri-environmental NGO) represented the farmer collectives in meetings with the governmental organisations. Government organisations are part of a dense network of various involved actors from different governmental levels (provincial, national, and European) and with different tasks (management, certifying, and controlling). There are also different nature organisations involved to monitor progress and to provide advice on monitoring and nature management. As part of this dense network, controlling agencies, such as the NVWA (Netherlands Food and Consumer Product Safety Authority), are involved to monitor ecological indicators and the measures taken at farm-level.

In addition to the formal structure of the new model, the collectives also had to build a good relationship with other actors involved, especially in light of the negative perceptions of the old policy. This took some time as, according to an interviewee from the farmer collective in Drenthe: "The whole social capital and the social system was absent. And now the collectives are there, it is a whole new social system. That is what needed to be built between each other; and they did this." A point that was also emphasised by the respondent from BoerenNatuur: "the farmer collectives have a hard job, but I have to say they are doing well in connecting with wide networks in the regions." While, also, a representative of the European Union states: "the motivation and will to learn and work collectively is great, we saw that during our visits." As such, the collective in Drenthe invested heavily in developing social relationships. This happened through meetings with individual farmers, farm visits, and various evening events for questions and discussions. However, most important was that the representative of the collective were easy to reach for questions, to discuss issues, or carry out the administration together. According to many respondents, this investment in the development of social relationships was considered as successful. The initial concerns by the involved governmental organisations and nature organisations about the motivation of the farmers to join the collective disappeared over time. Farmers also expressed strong motivations to stay involved. One farmer explained: "For me as a farmer it is important to also take care of nature, the landscape." While another stated: "That [taking care of the landscape] is what we already do for years, also with our management in the nearby nature area."

Despite the doubts about the motivation of farmers, the often critical nature organisations emphasised the importance of cooperation and a constructive attitude towards the farmer collectives. One of the reasons for this is that the new model has already created more interaction among farmers and between farmers and nature organisations, creating opportunities to share experiences, uncertainties, and opportunities.

Indeed, the interviewees from the farmers' collective and the representatives of the collectives (BoerenNatuur) shared the observation that, due to the establishment of the collective, the relationships changed towards more direct collaboration between the farmers and the collective, while the earlier, formal, and bureaucratic mode of interaction with the government had decreased. This was experienced 
as positive by all parties involved: "Now everything is done through the collective, they [the collective] come here and help you. We sit together. That is better than doing it alone". The farmers in our interviews particularly indicated that they appreciated that the 'bureaucratic' issues, such as digitalising and registering the size and type of their property, were now much easier to handle due to the establishment of the collective. The practical and positive experiences took away many initial uncertainties and contributed to a positive attitude towards the new agri-environmental policy; they were instrumental in creating trust in the people of the collective. While the collaboration evolved, a positive history, shared between different actors, started to take shape.

\subsection{Evolving Relationships}

As the cooperation with and within the collective developed, relationships started to evolve. One of the key issues identified in the interviews was that governmental authorities recognised that giving the collectives responsibilities and a certain extent of freedom in agri-environmental management, as well as learning from each other, sent a signal of trust towards the collectives and farmers. Or as an EU civil servant stated: "The cooperative structure has the advantage that you can use the knowledge exchange between farmers and their motivation." While a province representative stated: "the model is now functioning very solid. And because it is such a success we look for possibilities to extend it. That is, I think, very positive". Also, at the level of the collective, we see that the cooperative structure supported trust relations as it encouraged cooperation and interaction among farmers. This created a communicative space to share experiences and understand how fellow farmers were implementing nature management. These experiences stimulated interaction over a common goal and fostered interpersonal trust development among farmers. In other words, the new policy model and how it functioned was experienced as a signal of trust to the farmers by the Dutch government and stimulated the interaction at the level of the collective, creating interpersonal trust among farmers and within the farmers' collective in Drenthe, as well as institutional trust of farmers in the new model.

With the trust in the new policy model, stronger interpersonal trust relations started to evolve. This was especially fuelled by the shift towards collective actions. A collective feeling was developed through the shared experience, as indicated by several farmers during the interviews that they "love the landscape of Drenthe", leading to the shared idea that together they could take more responsibility for the landscape and achieve more. This shared experience appealed to the preferred identity of farmers as 'guardians of the Dutch landscape'. This experience was also shared by respondents from the farmer representative organisation, BoerenNatuur, and officials of the province. The latter also emphasised that this communal sense was grounded in the greater responsibilities now given to the farmers (collectives): "organising it in collectives gives more responsibility to farmers, but also more trust that they can do it together."

One of the aspects that was not experienced as very positive was the monitoring system. The main reason for this discomfort was that under the new policy, both the NVWA (Dutch Food Safety Authority) and the Stichting Certificering (certification institute) execute controlling and auditing. The representative of the collective in Drenthe expressed: "we don't like the control." This was confirmed by the respondent from Stichting Certificering: "the collectives cooperate but it is not with great enthusiasm." Therefore, although the new model gave greater responsibilities to the farmers, which was generally experienced as a sign of trust, the auditing had the opposite effect, as it was experienced as an expression of mistrust towards the farmers and the collective. This was especially the case as it provided a reminder of the experience of mistrust and control in the old model. This affected the trust in the new agri-environmental policy system, as one interviewee explained: "We see that people complain not about the organisation doing the auditing but about the policy system in general." Similarly, the interviewee from Stichting Certificering observed: "we notice especially a negative attitude when also the NVWA did an audit just before we came in. Then people saw this as a flaw in the system!" Due to these experiences, different interviewees perceived this discrepancy as a future risk for the agri-environmental policy. 
Interviewees, especially non-farmers, indicated that over time, trust between people became less important because the systems functioned so well. As a consequence, a sort of generalised trust towards the new agri-environmental policy started to emerge. Among other factors, this resulted in the situation that all actors showed a commitment to secure the budgets in the long-term. Furthermore, different governmental actors (province, Ministry of Agriculture), as well as the collective in Drenthe, explored opportunities to extend the collectives model into other policy areas, such as energy and climate.

The dominance of positive feelings does, however, not mean that there was no criticism of the new policy model. At the higher levels, between the ministry and national partners such as the NGO BoerenNatuur, interviewees indicated that there remained a sceptical attitude whether farmers were able to perform well within agri-environmental schemes. As one of the interviewees explained: "yes, you still notice a certain scientism towards farmers when talking about agri-environmental schemes". Especially the nature organisations were sceptical towards the policy model in general. As one of their respondents stated: "I see agri-environmental schemes as a short-term solution, you cannot make up on a few hectare what you mess up on the majority on of the land." Just as experiences of farmers with the monitoring, this observation was based on experiences with the old model. And, while BoerenNatuur aims to pass their trust in farmers on to higher levels, complaints about farmers lacking the ability to contribute to biodiversity pop up now and then. Similar perceptions could also be found at lower levels. While farmers and employees of AND (Agrarian Nature collective Drenthe) felt positive about the new agri-environmental policy, farmers still experienced occasional inconsistencies or 'hiccups'. When discussing this issue with them, most explained that these experiences reminded them of the old policy model and how they had been treated at that time (e.g., budget cuts), reviving emotional responses, giving some a reason not to trust the new policy and the actors involved. This shows that despite the generally positive trust dynamics and a more open environment in which people can learn from mistakes and improve their work, changes in the policy and any inconsistency experienced evoked, at least in some respondents, feelings of mistrust, which negatively influenced trust in the new policy and the collective.

\subsection{Wider Context and Future}

Most farmers indicated that they had intense business relationships with their agrarian cooperatives. After working with the new agri-environmental policy for a few years, it was experienced that also FrieslandCampina (a milk cooperative) and AgriFirm (an agricultural cooperative) had a positive attitude towards the new agri-environmental policy. As the interviewee from FrieslandCampina explained: "yes, we give additional financial support when farmers take part in agri-environmental schemes." This shows, in line with the farmers' account, that these cooperatives provided financial incentives to produce in more sustainable ways (for example, the farmers received a bonus of one cent per litre of sustainably-produced milk). This indicates broader support among actors in the value chains for agri-environmental management and the new policy model, with a potential to further enhance trust and confidence in the new model among both farmers and other actors.

Another important group, the local communities living in areas around farmers, also influenced experiences with the new policy positively. Different farmers explained that flowers around their fields or little patches of natural areas on their land were appreciated by local communities. In addition, several farmers also shared that because of the agri-environmental policy they were involved in, schools and the local communities approached them with requests to visit the farm: "The schools see that we have fields with nice flowers, so they approached me. Now I regularly have a group of 30 children visiting our farm. This is very important for me as it is great to show others the work we do and it increases our license to produce." Other farmers indicated that they were in contact with local ornithologists. As a result, several farmers felt that the agri-environmental policy added to their license to produce, creating more opportunities to connect to local communities and, therefore, had a positive impact on the farm more broadly.

The positive experiences with the new collective model for agri-environmental management signalled to many policy-makers that the model has potential for application in other policy areas. 
Especially policy-makers from the province saw such a potential: "The current policy is solid and operational, now we are looking at extending it to other fields, such as climate." Despite this positive attitude by many interviewees, some concerns were expressed as well, in particular with regard to the future of the policy. One respondent saw the collective model as "the last chance for agri-environmental management." Other respondents vented doubt whether the collective model would be successful in ecological terms, for example, a civil servant of the EU: "We are positive about the new model, but also cautious as we do not have the results yet of the ecological monitoring." The main concern expressed was that if the results turn out to be disappointing, the policy would need to be revised again or even cancelled (see for an overview of findings Figure 3). Such a policy change would have the potential to undermine the trust relationships built around and through the new policy model.
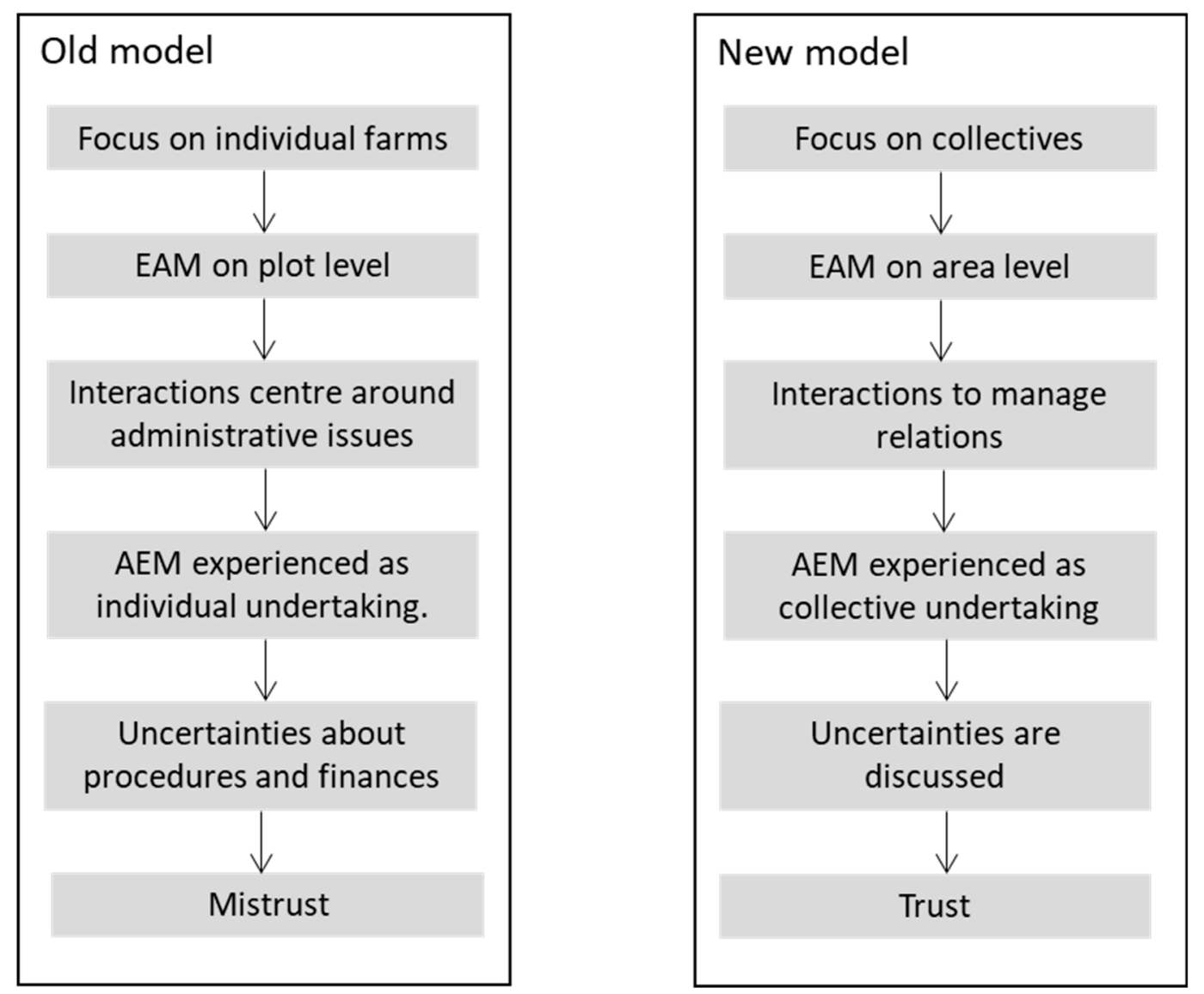

Figure 3. Schematic and generalised representation of experiences with the old and new agri-environmental management (AEM) models and their consequences.

\section{Discussion}

This research explored the development of interpersonal and institutional trust relationships around agri-environmental management in the Netherlands after the shift towards a new, collective policy model. The findings are confined to one case and quantitative generalisability is, therefore, limited. However, with regard to agri-environmental schemes and trust, our findings have important implications for theory and policy. The results of our study show how, at least in the case of agri-environmental management in Drenthe, both interpersonal trust and institutional trust were affected by the institutional design of the agri-environmental scheme. Our findings support the proposition that both interpersonal trust and trust in institutions are highly relevant for agri-environmental management [59-61] and for collective action for addressing environmental issues more broadly $[47,62,63]$. More specifically, our case shows that institutional designs can encourage particular forms of interaction and collectiveness, and thereby influence interpersonal trust development 
between actors involved. Whereas the old policy model was designed for minimal interaction through audit and control, the new policy model strongly stimulated interaction and cooperation, although audits and control still remain in place. Handling uncertainties and disappointments, therefore, becomes a key issue. Overall, the findings shed light on the complex and dynamic interplay between interpersonal and institutional trust.

The results also show that trust in institutions not only develops through performance [64] but also that the institutional design of a policy can be a signal of trust towards actors (in this case, towards the farmers), thereby encouraging reciprocal trust in the policy. The institutional trust in the policy appeared to be grounded in decreased feelings of uncertainty and the assignment of responsibility to the collectives. This necessitated more frequent and more horizontal interaction, which, in turn, created a communicative space for the development of new and stronger interpersonal trust relations between all actors involved. The shared experience of successful cooperation, in turn, enabled the development of more affinitive aspects of trust, such as shared feelings of collectiveness, efforts, and identities. In addition, the case analysis shows that positive experience with the system, its structures and procedures, as well as between actors, mutually reinforced each other, creating positive feedback loops and fostering trust in people and the policy model. This finding suggests that institutional design can address mismatches between interpersonal and institutional trust and related experiences of uncertainties, vulnerability, and disempowerment, which are often associated with avoidance and lack of participation $[26,65,66]$.

It has been argued that trust in institutions is essential for their functioning [67-69]. However, it remains unclear how trust plays a role in the context of emerging institutions or institutional change when people are not familiar with the novel institutions. By studying the role of trust in the establishment of a new policy model, our results suggest that in cases of institutional change, system design and use in connection to the wider social and institutional context shape trust development. Appropriate institutional designs can encourage trust, especially if it allows for connections to wider social systems that are important for individual actors within a policy. However, the trust effects depend also on a shared discourse; for instance, strong dispositional trust or the general tendency to trust each other [26] will facilitate connections with wider networks. The findings, therefore, suggest that institutional designs can be a precondition rather than a determining factor for trust development during institutional change [47]. Such insights may be highly relevant for policies that aim for trust development, which are often designed along principles of participation and interactive policy processes [70-73]. Institutional designs that communicate trust through delegating responsibilities and reduce bureaucratic burdens associated with uncertainties and risk might be an alternative way for policies to create trust and social capital.

The results also bring attention to the way in which path dependencies of the governance systems impact trust dynamics. In the case of agri-environmental policy in Drenthe, the negative experiences with the old model lingered on and kept some organisations in the critical camp. Negative experiences from the old model resulted in a continuing emphasis on auditing and control, which contrasted efforts for trust development under the new model. Farmers recalled negative experiences with the old model when facing 'hiccups', which undermined the feeling of collectiveness and undermined trust development. Thus, on the one hand, we found that trust can develop under institutional change and within a particular institutional design $[63,74-76]$. On the other hand, however, it is clear that path dependencies and policy legacies can constrain trust development. In other words, prevalent expectations about the institutional arrangements learned under the old model continue to play a role in the design and use of the new model. This has an impact not only on collaboration in general and how it is organised, as people can remain critical about control mechanisms, but has an especially strong influence on trust dynamics, which are strongly built upon past experiences and their interpretation [42].

The experiences so far, and the trust developed in relation to different policy models in agri-environmental management, requires a more critical look towards the evaluation of such policies. 
Although this study was not focused on ecological targets, different interviewees raised the question: "What would happen with the new policy when biodiversity targets are not met?" In other words, despite the positive outcome of the new policy in social terms and for collective action, its future is likely to depend on its ecological achievements. Therefore, and based on the impact of the new model on trust development, we argue for a broadening of policy evaluations that take trust development into account. Especially, as lessons learned from such evaluations might generate valuable insights on how to encourage further trustful interaction for sustainable farming practices and a more sustainable future for rural areas.

The findings of this study underpin the need to develop agri-environmental schemes at a landscape level. Whereas other studies have shown the benefits of a landscape-based approach for ecological reasons [2], this study shows that there are also social reasons for working at landscape level: it involves different stakeholders, can help to create the conditions that facilitate shared responsibilities, cooperation, mutual learning, and the flexibility to deal with the uncertainties that actors experience when they decide to participate in an agri-environmental scheme.

Yet, at the same time, it should be recognised that creating suitable conditions for such schemes does not necessarily lead to more trust. First of all, the possibilities of introducing a new model and its impact depend on the context in which the model is developed and introduced. Existing trust relations between actors involved, specific socio-economic circumstances, and the particularities of the physical environment can be more or less supportive of a new model. Furthermore, one needs to take into account that if the ecological or the farm-economic results are not positive, for whatever reason, this will put pressure on the model and likely on the relations between the involved stakeholders. What matters, then, is how these stakeholders deal with disappointing results. Here, our case shows that institutional design influences the interrelation between interpersonal and institutional trust. More specifically, if all actors feel that an agri-environmental scheme works well, it is likely to enhance institutional trust. In contrast, if things do not go well, inter-personal trust depends on the way in which actors deal with disappointments. In such instances, which are likely to be faced by all policies and its actors, the focus is relevant. A focus on compliance and control might create tensions between actors and a decline of trust in the overall model. However, based on inter-personal trust, actors might be more willing to accept uncertainties and disappointments and to learn and sustain institutional trust $[47,77-79]$.

\section{Conclusions}

This study addressed the question: "How does the institutional design of collective agri-environmental policy influence interpersonal and institutional trust and their interrelation?" Through this question, we aimed to contribute to a better understanding of the empirically underexplored relation between institutional trust and interpersonal trust. We studied this question by focusing on agri-environmental policies and practices in the province of Drenthe. Based on our results, we conclude that institutional designs that reflect trust in the actors by delegating tasks and responsibilities and by reducing uncertainties can foster interpersonal trust between actors involved. In turn, these trust experiences can further strengthen trust in the institutional design and thereby foster collective action for agri-environmental management. More specifically, our study brings attention to three important issues that require attention in the (re)design of agri-environmental schemes, contributing not only to these debates but also to the broader theoretical debate and understanding of the design of institutional arrangements in general and the vital role of trust in these contexts.

Firstly, the development of both interpersonal and institutional trust shows strong path dependencies. Previous experiences, in our case, with the old policy model and the trust levels that are based on these experiences, influence both the process of redesign, as well as the performance of new institutions. Secondly, we can conclude that institutional design, to a large extent, shapes the relations and interactions between different actors. In the old model, the institutions created a system in which individual farmers made an agreement with the Dutch government, and the government 
acted as controller and financer. This design guided the interactions towards conversations about control, auditing, and finances. Consequently, both parties developed an attitude of mutual mistrust, particular if things did not run smooth. The new policy model created more scope for interaction. In addition, the model guided interactions towards collective action: learning and doing things together. This created more opportunities to share uncertainties, discuss issues, and to develop mutual trust. Moreover, it resulted in the coupling of agri-environmental schemes to other institutions and networks, such as local communities and suppliers and retailers. These links created new positive experiences, which, in turn, enhanced institutional trust. Thirdly, we can conclude that the institutional designs have a great influence in dealing with uncertainties and disappointments. A narrow focus on audit and control made it much more difficult to deal with disappointing results, to learn, and improve the scheme, while an institutional design that places more emphasis on collective responsibilities and mutual learning guided interactions towards a dialogue between the different actors, whereby inter-personal trust relations helped to sustain institutional trust. Since all actors trust their collective efforts, they are more inclined to consider disappointing outcomes as a coincidence to learn from.

These three lines of findings could be explored further in future research, focusing on a better understanding of path dependencies and trust, how interactions across (social) networks contribute to trust, and how mutual learning fosters trust development. As our study is based on a single case study, conducting similar studies, in other geographical, institutional, and policy set-ups could, therefore, create interesting and additional insights. Especially comparative studies, across regions or policy areas within countries, but also across the European Union could be highly relevant to come to more in-depth findings and relevant insights to national and European policies contexts, for example, in relation to the further development of the Rural Development Program. Follow-up studies with a larger $n$ could add to the quantitative generalisability of the results, again, in national or European contexts.

With the increased attention for local realities, integrating social and agricultural values, and resilient agricultural systems (see for instance the EU Common Agricultural Policy, CAP), we argue that collective models at landscape level have great potential. Especially, our results show how such institutional designs can communicate trust and create a context in which trust can prosper so that agri-environmental policies can foster broader social development in rural areas with room to connect to other networks and initiatives. Such findings are highly relevant as more and more rural policies have a strong integrative character with an increasing need to connect agricultural livelihoods, biodiversity, landscape values, and natural resource management at the landscape level.

Author Contributions: Conceptualisation and set-up of the study, J.R.d.V., E.v.d.Z., R.B. and P.H.F.; methodology, J.R.d.V., E.v.d.Z., R.B. and P.H.F.; field work and data analyses, J.R.d.V., E.v.d.Z. and R.K.; writing-original draft preparation, J.R.d.V., E.v.d.Z., R.B., R.K.; writing—review and editing J.R.d.V., P.H.F., R.B. and E.v.d.Z.

Funding: This research was funded by the Resilience Investment Theme of Wageningen University and Research, the Netherlands.

Conflicts of Interest: The authors declare no conflict of interest.

\section{References}

1. Burton, R.J.F.; Paragahawewa, U.H. Creating culturally sustainable agri-environmental schemes. J. Rural Stud. 2011, 27, 95-104. [CrossRef]

2. Van Dijk, W.F.A.; Lokhorst, A.M.; Berendse, F.; de Snoo, G.R. Factors underlying farmers' intentions to perform unsubsidised agri-environmental measures. Land Use Policy 2016, 59, 207-216. [CrossRef]

3. Kleijn, D.; Berendse, F.; Smit, R.; Gilissen, N. Agri-environment schemes do not effectively protect biodiversity in dutch agricultural landscapes. Nature 2001, 413, 723. [CrossRef] [PubMed]

4. Agri-Environmental Schemes: How to Enhance the Agriculture-Environment Relationship, 57th ed.; European Commission DG Environment: Bristol, UK, 2017.

5. Westerink, J.; Jongeneel, R.; Polman, N.; Prager, K.; Franks, J.; Dupraz, P.; Mettepenningen, E. Collaborative governance arrangements to deliver spatially coordinated agri-environmental management. Land Use Policy 2017, 69, 176-192. [CrossRef] 
6. Lastra-Bravo, X.B.; Hubbard, C.; Garrod, G.; Tolón-Becerra, A. What drives farmers' participation in eu agri-environmental schemes?: Results from a qualitative meta-analysis. Environ. Sci. Policy 2015, 54, 1-9. [CrossRef]

7. Taylor, B.; Van Grieken, M. Local institutions and farmer participation in agri-environmental schemes. J. Rural Stud. 2015, 37, 10-19. [CrossRef]

8. Riley, M.; Sangster, H.; Smith, H.; Chiverrell, R.; Boyle, J. Will farmers work together for conservation? The potential limits of farmers' cooperation in agri-environment measures. Land Use Policy 2018, 70, 635-646. [CrossRef]

9. Alló, M.; Loureiro, M.L.; Iglesias, E. Farmers' preferences and social capital regarding agri-environmental schemes to protect birds. J. Agric. Econ. 2015, 66, 672-689. [CrossRef]

10. Villanueva, A.; Targetti, S.; Schaller, L.; Arriaza, M.; Kantelhardt, J.; Rodriguez-Entrena, M.; Bossi-Fedrigotti, V.; Viaggi, D. Assessing the role of economic actors in the production of private and public goods in three eu agricultural landscapes. J. Environ. Plan. Manag. 2015, 58, 2113-2136. [CrossRef]

11. Ge, L.; Anten, N.P.; van Dixhoorn, I.D.; Feindt, P.H.; Kramer, K.; Leemans, R.; Meuwissen, M.P.; Spoolder, H.; Sukkel, W. Why we need resilience thinking to meet societal challenges in bio-based production systems. Curr. Opin. Environ. Sustain. 2016, 23, 17-27. [CrossRef]

12. Ravnborg, H.M.; Westermann, O. Understanding interdependencies: Stakeholder identification and negotiation for collective natural resource management. Agric. Syst. 2002, 73, 41-56. [CrossRef]

13. Van Bueren, E.M.; Klijn, E.H.; Koppenjan, J.F. Dealing with wicked problems in networks: Analyzing an environmental debate from a network perspective. J. Public Adm. Res. Theory 2003, 13, 193-212. [CrossRef]

14. Rydin, Y.; Pennington, M. Public participation and local environmental planning: The collective action problem and the potential of social capital. Local Environ. 2000, 5, 153-169. [CrossRef]

15. Zee, E.V.D. Disciplining private standards under the sps and tbt agreement: A plea for market-state procedural guidelines. J. World Trade 2018, 52, 393-414.

16. Rodríguez, J.; Beard, T.D., Jr.; Bennett, E.; Cumming, G.; Cork, S.; Agard, J.; Dobson, A.; Peterson, G. Trade-offs across space, time, and ecosystem services. Ecol. Soc. 2006, 11, 28. [CrossRef]

17. Atkinson, G.; Bateman, I.; Mourato, S. Recent advances in the valuation of ecosystem services and biodiversity. Oxf. Rev. Econ. Policy 2012, 28, 22-47. [CrossRef]

18. Ostrom, E. Analyzing collective action. Agric. Econ. 2010, 41, 155-166. [CrossRef]

19. Rothstein, B. Just Institutions Matter: The Moral and Political Logic of the Universal Welfare State; Cambridge University Press: Cambridge, UK, 1998.

20. Ostrom, E. A behavioral approach to the rational choice theory of collective action: Presidential address, american political science association, 1997. Am. Political Sci. Rev. 1998, 92, 1-22. [CrossRef]

21. Cox, J.C.; Friedman, D.; Gjerstad, S. A tractable model of reciprocity and fairness. Games Econ. Behav. 2007, 59, 17-45. [CrossRef]

22. Frohlich, N.; Oppenheimer, J.A. Choosing Justice: An Experimental Approach to Ethical Theory; University of California Press: Berkeley, CA, USA, 1993; Volume 22.

23. Hotte, N.; Kozak, R.; Wyatt, S. How institutions shape trust during collective action: A case study of forest governance on haida gwaii. For. Policy Econ. 2019, 107, 101921. [CrossRef]

24. Coleman, K.; Stern, M.J. Exploring the functions of different forms of trust in collaborative natural resource management. Soc. Nat. Resour. 2018, 31, 21-38. [CrossRef]

25. Vaske, J.J.; Absher, J.D.; Bright, A.D. Salient value similarity, social trust and attitudes toward wildland fire management strategies. Hum. Ecol. Rev. 2007, 14, 223-232.

26. Stern, M.J.; Coleman, K.J. The multidimensionality of trust: Applications in collaborative natural resource management. Soc. Nat. Resour. 2015, 28, 117-132. [CrossRef]

27. Davenport, M.A.; Leahy, J.E.; Anderson, D.H.; Jakes, P.J. Building trust in natural resource management within local communities: A case study of the midewin national tallgrass prairie. Environ. Manag. 2007, 39, 353-368. [CrossRef]

28. Lijeblad, A.; Borrie, W.T.; Watson, A.E. Determinants of trust for public lands: Fire and fuels management on the bitterroot national forest. Environ. Manag. 2009, 43, 571-584. [CrossRef]

29. Asveld, L.; Ganzevles, J.; Osseweijer, P. Trustworthiness and responsible research and innovation: The case of the bio-economy. J. Agric. Environ. Ethics 2015, 28, 571-588. [CrossRef] 
30. De Vries, J.; van Bommel, S.; Peters, K. Trust at a distance-Trust in online communication in environmental and global health research projects. Sustainability 2018, 10, 4005. [CrossRef]

31. Möllering, G. The nature of trust: From georg simmel to a theory of expectation, interpretation and suspension. Sociology 2001, 35, 403-420. [CrossRef]

32. Zand, D.E. Reflections on trust and trust research: Then and now. J. Trust Res. 2016, 6, 63-73. [CrossRef]

33. Uslaner, E.M. Trust and social bonds: Faith in others and policy outcomes reconsidered. Political Res. $Q$. 2004, 57, 501-507. [CrossRef]

34. Rousseau, D.M.; Sitkin, S.B.; Burt, R.S.; Camerer, C. Not so different after all: A cross-discipline view of trust. Acad. Manag. Rev. 1998, 23, 393-404. [CrossRef]

35. Uslaner, E.M.; Conley, R.S. Civic engagement and particularized trust: The ties that bind people to their ethnic communities. Am. Politics Res. 2003, 31, 331-360. [CrossRef]

36. Lewicki, R.J.; Tomlinson, E.C.; Gillespie, N. Models of interpersonal trust development: Theoretical approaches, empirical evidence, and future directions. J. Manag. 2006, 32, 991-1022. [CrossRef]

37. Lewicki, R.; Bunker, B. Developing and maintaining trust in work relationships. In Trust in Organizations; Kramer, R., Tyler, T., Eds.; Sage: Thousand Oaks, CA, USA, 1996; pp. 114-139.

38. Van Oortmerssen, L.A.; van Woerkum, C.M.J.; Aarts, N. The visibility of trust: Exploring the connection between trust and interaction in a dutch collaborative governance boardroom. Public Manag. Rev. 2014, 16, 666-685. [CrossRef]

39. Idrissou, L.; van Paassen, A.; Aarts, N.; Vodouhè, S.; Leeuwis, C. Trust and hidden conflict in participatory natural resources management: The case of the pendjari national park (pnp) in benin. For. Policy Econ. 2013, 27, 65-74. [CrossRef]

40. De Vries, J.; van Bommel, S.; Blackmore, C.; Asano, Y. Where there is no history: How to create trust and connection in learning for transformation in water governance. Water 2017, 9, 130. [CrossRef]

41. O'Brein, R. Trust, Releasing the Energy to Succeed; John Wiley \& Sons: Chichester, UK, 2001.

42. De Vries, J.R.; Aarts, N.; Lokhorst, A.M.; Beunen, R.; Munnink, J.O. Trust related dynamics in contested land use: A longitudinal study towards trust and distrust in intergroup conflicts in the baviaanskloof, south africa. For. Policy Econ. 2015, 50, 302-310. [CrossRef]

43. Zucker, E.M. Forest of Struggle: Moralities of Remembrance in Upland Cambodia; University of Hawaii Press: Honolulu, HI, USA, 2013; p. 233.

44. Rus, A.; Iglič, H. Trust, governance and performance: The role of institutional and interpersonal trust in sme development. Int. Sociol. 2005, 20, 371-391. [CrossRef]

45. Woodhill, J. Capacities for institutional innovation: A complexity perspective. IDS Bull. 2010, 41, 47-59. [CrossRef]

46. Fuglsang, L.; Jagd, S. Making sense of institutional trust in organizations: Bridging institutional context and trust. Organization 2015, 22, 23-39. [CrossRef]

47. Luhmann, N. Trust and Power; Wiley: Chichester, UK, 1979.

48. Luhmann, N. Familiarity, confidence, trust: Problems and alternatives. In Trust: Making and Breaking Cooperative Relations; Gambetta, D., Ed.; University of Oxford: Oxford, UK, 2000.

49. Ellickson, R.C. Order without Law: How Neighbors Settle Disputes; Harvard University Press: Cambridge, MA, USA, 1991.

50. Beunen, R.; Patterson, J.; Van Assche, K. Governing for resilience: The role of institutional work. Curr. Opin. Environ. Sustain. 2017, 28, 10-16. [CrossRef]

51. Child, J.; Möllering, G. Contextual confidence and active trust development in the chinese business environment. Organ. Sci. 2003, 14, 69-80. [CrossRef]

52. Giddens, A. The Consequences of Modernity; John Wiley \& Sons: Hoboken, NJ, USA, 2013.

53. Gilson, L. Health systems and institutions. In Health Systems in Low-and Middle-Income Countries: An Economic and Policy Perspective; Oxford University Press: Oxford, UK, 2012.

54. Vries, J.R.D. Understandig Trust: Longitudinal Studies on Trust Dynamics in Governance Interactions; Wageningen University: Wageningen, The Netherlands, 2014.

55. Yin, R.K. Case Study Research and Applications: Design and Methods; Sage publications: Thousand Oaks, CA, USA, 2017.

56. Flyvbjerg, B. Five misunderstandings about case-study research. Qual. Inq. 2006, 12, 219-245. [CrossRef] 
57. Raad voor de leefomgeving en infrastructuur. Onbeperkt Houdbaar. Naar een Robuust Natuurbeleid; RLI: Den Haag, The Netherlands, 2013.

58. Melman, D.; Van Doorn, A.; Schootman, A.; Van der Zee, F.; Blanken, H.; Martens, S.; Sierdsema, H.; Smidt, R. Nieuw Stelsel Agrarisch Natuurbeheer; Alterra: Wageningen, The Netherlands, 2015.

59. De Krom, M.P.M.M. Farmer participation in agri-environmental schemes: Regionalisation and the role of bridging social capital. Land Use Policy 2017, 60, 352-361. [CrossRef]

60. Pavlis, E.S.; Terkenli, T.S.; Kristensen, S.B.P.; Busck, A.G.; Cosor, G.L. Patterns of agri-environmental scheme participation in europe: Indicative trends from selected case studies. Land Use Policy 2016, 57, 800-812. [CrossRef]

61. Polman, N.B.P.; Slangen, L.H.G. Institutional design of agri-environmental contracts in the european union: The role of trust and social capital. Njas-Wagening. J. Life Sci. 2008, 55, 413-430. [CrossRef]

62. Kjærnes, U. Trust and distrust: Cognitive decisions or social relations? J. Risk Res. 2006, 9, 911-932. [CrossRef]

63. Ostrom, E. A general framework for analyzing sustainability of social-ecological systems. Science 2009, 325, 419-422. [CrossRef]

64. Beunen, R.; Patterson, J.J. Analysing institutional change in environmental governance: Exploring the concept of 'institutional work'. J. Environ. Plan. Manag. 2019, 62, 12-29. [CrossRef]

65. Mayer, R.C.; Davis, J.H.; Schoorman, F.D. An integrative model of organizational trust. Acad. Manag. Rev. 1995, 20, 709-734. [CrossRef]

66. Kumar, A.; Paddison, R. Trust and collaborative planning theory: The case of the scottish planning system. Int. Plan. Stud. 2000, 5, 205-223. [CrossRef]

67. Hardin, R. Do we want trust in government? Democr. Trust 1999, 22-41. [CrossRef]

68. Schoorman, F.D.; Mayer, R.C.; Davis, J.H. An integrative model of trust: past, present, future. Acad. Manag. Rev. 2007, 32, 344-354. [CrossRef]

69. Bachmann, R. Trust, power and control in trans-organizational relations. Organ. Stud. 2001, 22, 337-365. [CrossRef]

70. Tsang, S.; Burnett, M.; Hills, P.; Welford, R. Trust, public participation and environmental governance in hong kong. Environ. Policy Gov. 2009, 19, 99-114. [CrossRef]

71. Bulkeley, H.; Mol, A.P. Participation and environmental governance: Consensus, ambivalence and debate. Environ. Values 2003, 12, 143-154. [CrossRef]

72. Wang, X.; Wan Wart, M. When public participation in administration leads to trust: An empirical assessment of managers' perceptions. Public Adm. Rev. 2007, 67, 265-278. [CrossRef]

73. Hurlbert, M.; Gupta, J. The split ladder of participation: A diagnostic, strategic, and evaluation tool to assess when participation is necessary. Environ. Sci. Policy 2015, 50, 100-113. [CrossRef]

74. Kramer, R.M.; Brewer, M.B.; Hanna, B.A. Collective trust and collective action. In Trust in Organizations: Frontiers of Theory and Research; Sage: Thousand Oaks, CA, USA, 1996; pp. 357-389.

75. Raymond, L. Cooperation without trust: Overcoming collective action barriers to endangered species protection. Policy Stud. J. 2006, 34, 37-57. [CrossRef]

76. Pittman, J. The struggle for local autonomy in biodiversity conservation governance. J. Environ. Plan. Manag. 2019, 62, 172-188. [CrossRef]

77. Luhmann, N.; Kastner, F.; Schiff, D. Law as a Social System; Oxford University Press on Demand: Oxford, UK, 2004.

78. North, D.C. Understanding Processes of Economic Change; Princeton University Press: Princeton, NY, USA, 2005.

79. Stein, H. Financial liberalisation, institutional transformation and credit allocation in developing countries: The world bank and the internationalisation of banking. Camb. J. Econ. 2009, 34, 257-273. [CrossRef]

(C) 2019 by the authors. Licensee MDPI, Basel, Switzerland. This article is an open access article distributed under the terms and conditions of the Creative Commons Attribution (CC BY) license (http://creativecommons.org/licenses/by/4.0/). 